\title{
Enzyme linked immunosorbent assay for detecting adenoviruses in stool specimens: comparison with electron microscopy and isolation
}

\author{
A L Martin, G Kudesia
}

\begin{abstract}
A commercial enzyme linked immunosorbent assay (ELISA) for detection of adenoviruses in stool samples was compared with the use of electron microscopy and isolation in Graham 293 cells. Although specific, the ELISA was less sensitive than both electron microscopy and isolation. The ELISA had an overall sensitivity of $78 \%$ and a specificity of $100 \%$. The sensitivity was related to the amount of virus particles present in the stool sample, increasing to $90 \%$ with about $10^{7}$ viral particles $/ \mathrm{ml}$ of stool. The ELISA was easy to perform, requiring no instrumentation, and is a useful first line test for detection of adenoviruses in stool samples, especially in laboratories without access to an electron microscope.

Wider use of ELISAs should help in evaluating the role of adenoviruses in viral gastroenteritis.
\end{abstract}

Adenovirus are often isolated from the stools of children with or without gastroenteritis. Although several outbreaks of gastroenteritis due to adenoviruses have been described, their role in sporadic cases of gastroenteritis remains uncertain. Serotypes 40 and 41 have recently been strongly linked with gastroenteritis, ${ }^{1}$ although some workers suggest that other serotypes may also cause gastroenteritis. ${ }^{2}$ The diagnosis of adenoviral gastroenteritis is limited to electron microscopical examination as serotypes $\mathbf{4 0}$ and 41 are not easily grown in cell culture, hence the name fastidious adenoviruses. We have evaluated a group specific commercial adenovirus ELISA NovoBiolabs (formerly Boots Celltech) and compared it with electron microscopy and isolation in tissue culture.

\section{Methods}

One hundred and thirteen stool samples were examined by the new adeno ELISA method. Forty five stools were from 37 children, all of whom had diarrhoea, there were two or more serial specimens from six patients, and all the stools were positive for adenovirus by electron microscopical examination. Sixty eight stools were included as controls, of which 18 were negative controls taken from children without diarrhoea, 50 stools were from children with diarrhoea, 40 stools were negative by electron microscopical examination, and 10 had other viral pathogens. To test for cross reaction with staphylococcal protein A in the enzyme im- munoassay a $10^{-1}$ to $10^{-6}$ dilution of lyophilised Cowan strain Staphylococcus aureus (Sigma) was made in a negative stool sample and $100 \mu \mathrm{l}$ of each dilution treated as sample.

\section{ELECTRON MICROSCOPY}

Electron microscopical examination was performed after $10 \%$ PBS extraction of stool; this extract was then concentrated by ultracentrifugation at $200000 \times g$ for 60 minutes. The pellet was suspended in $1 \%$ Bacitracin and negatively stained with phosphotungstic acid at $\mathrm{pH} 7$ and then examined at a magnification of 57000 in a Philips 301 electron microscope. The quantity of virus present was scored on a scale of occasional to $4+$.

\section{ELISA}

Boots Celltech IDEIA adenovirus enzyme immunoassay was performed according to the manufacturer's instructions. This is a solid phase sandwich type assay. Breakaway microwells are coated with a murine monoclonal antibody against the group reactive hexon antigen of adenovirus. Diluted faecal sample $(100 \mu \mathrm{l})$ was then added to each well with $100 \mu \mathrm{l}$ of enzyme conjugate. After 60 minutes of incubation at room temperature the sample well was washed with deionised water to remove unbound specimen and excess enzyme labelled antibodies. Enzyme substrate (urea peroxide) and chromogen (tetramethyl benzidine) were then added to the wells and incubated for 10 minutes at room temperature: any bound enzyme conjugate in the wells converts the colourless substrate to a blue colour, signifying a positive reaction. The plates were read at $450 \mathrm{~nm}$ after stopping the reaction with $1 \mathrm{~N}$ sulphuric acid after $10 \mathrm{~min}$ utes. Positive and negative controls were included in each run.

\section{CELL CULTURE}

All stool extracts were cultured in Graham 293 cell line ${ }^{3}$ which supports the growth of faecal adenoviruses. The cells were grown in minimal essential medium (MEM) with $10 \%$ fetal calf serum (FCS), and maintained in MEM with $1 \% \mathrm{FCS}$. The inoculum was adsorbed at $37^{\circ} \mathrm{C}$ for one hour, after which the maintenance medium was added. The tubes were examined daily. The presence of adenovirus was confirmed by the appearance of typical cytopathic effects, electron microscopical examination of the tissue culture fluid, or by ELISA. 
Table 1 Correlation of adenovirus EIA with electron microscopy

\begin{tabular}{lcclc}
\hline EM score & No of stools & EIA & EIA & Sensitivity (\%) \\
\hline $4+$ & 2 & 2 & 0 & 100 \\
$3+$ & 6 & 6 & 0 & 100 \\
$2+$ & 11 & 8 & 1 & 91 \\
$1+$ & 9 & $9 \star$ & 1 & 89 \\
Occ & 17 & & & 53 \\
\hline
\end{tabular}

* Six weak positive

†Occasional $=$ about $10^{6}$ particles $/ \mathrm{ml}$

$1+=$ about $10^{7}$ particles $/ \mathrm{ml}$

$2+=$ about $10^{8}$ particles $/ \mathrm{ml}$

(

$4+=$ about $10^{10}$ particles $/ \mathrm{ml}$

\section{Results}

Thirty five out of $45(78 \%)$ stool samples positive for adenovirus electron microscopical examination were also positive by ELISA. Table 1 shows the electron microscopy (EM) score of the stool samples positive and negative by enzyme immunoassay (EIA), the sensitivity of which was related to the number of virus particles present in the stool. This has also been observed with Rotavirus ELISA. ${ }^{4}$ The ELISA had a sensitivity of $92.8 \%$ when stools with a score of $1+$ or above were considered. The result of electron microscopy was regarded as the true result and the positive predictive value (PPV) and negative predictive value (NPV) calculated using the formulae:

$$
\text { PPV of EIA }=\mathrm{EIA}+, \mathrm{EM}+/ \mathrm{EIA}+
$$$$
\text { NPV of EIA }=\mathrm{EIA}-, \mathrm{EM}-/ \mathrm{EIA}-
$$

The PPV of the EIA compared with electron microscopy, was $100 \%$ and the NPV was $87 \%$. The NPV was $97 \%$, however, if only stools with a score of $1+$ or more were considered. All 68 control stools with no adenovirus detected at electron microscopy were negative by EIA and tissue culture. The $10^{-1}$ to $10^{-6}$ dilutions of $S$ aureus in the negative stool samples were all unreactive in the EIA. The EIA therefore had a specificity of $100 \%$.

Forty two of the above 45 stools were available for isolation in Graham 293 cells; adenovirus was isolated from 38 . The four stools from which adenoviruses were not isolated had an electron microscopy score of occasional $(n=2), 1+(n=1)$, and $2+(n=1)$, respectively. There was therefore a very close correlation between isolation in Graham 293 cells and electron microscopy (table 2).

Table 2 Comparison of electron microscopy, cell culture, and EIA for detection of faecal adenoviruses

\begin{tabular}{lllc}
\hline $\begin{array}{l}\text { Electron } \\
\text { microscopy }\end{array}$ & Cell culture & EIA & $\begin{array}{l}\text { No of } \\
\text { samples }\end{array}$ \\
\hline+ & NA & + & 3 \\
+ & + & + & 32 \\
+ & + & - & 6 \\
+ & - & - & 4 \\
- & - & - & 68 \\
\hline
\end{tabular}

Discussion

The adenovirus serotypes 40 and 41 have recently been associated with viral gastroenteritis. As these viruses do not grow in cell culture used routinely in most diagnostic laboratories infection with them is going to be missed unless electron microscopy is available. An ELISA has the advantage of not requiring expensive instrumentation and being rapid and easy to perform. In our hands the new IDEIA had a specificity of $100 \%$. Although the manufacturers state that the presence of protein A may give false positive reactions, we found no experimental evidence of this after artificially adding $S$ aureus to a negative stool sample. Furthermore, staphylococcal enterocolitis in children is extremely rare, ${ }^{5}$ and therefore the likelihood of staphylococcal protein A being present in a clinical sample is very low.

The overall sensitivity of $78 \%$ was disappointing, but it increased with the number of viral particles $/ \mathrm{ml}$ of stool, reaching $100 \%$ with about $10^{9}-10^{10}$ viral particles $/ \mathrm{ml}$ of stool sample. In our group of patients there was a direct relation between the number of virus particles being shed in the stool and the clinical importance-that is, the severity of illness and association with other enteric pathogens. It may be argued, therefore, that the ELISA will be useful in detecting clinically important infections.

Type specific ELISA (serotypes 40 and 41 ) are not widely available in this country but have been valuable in assessing the role of these viruses in gastroenteritis. Adenoviruses have been reported in $13 \%$ and $8 \%$ of all stool samples from children with diarrhoea from Sweden ${ }^{1}$ and Glasgow, ${ }^{6}$ respectively, and may make up to $22 \%$ of all stools positive by electron microscopy (G Kudesia, unpublished observations). There is therefore a need for a screening test for adenovirus gastroenteritis, especially in laboratories without access to an electron microscope.

The group specific adeno EIA would be an appropriate screening test, but a confirmation step for 40 and 41 by neutralisation would be useful as that would enable the role of the higher adenovirus serotypes to strengthen in viral gastroenteritis, and at the same time the role of other adenoserotypes in viral gastroenteritis could be evaluated further.

1 Uhnoo I, Wadell G, Svensson L, Johansson ME. Importance of enteric adenoviruses $\mathbf{4 0}$ and 41 in acute gastroenteritis in infants and young children. J Clin Microbio 1984;20:365-72.

2 Bhan MK, Raj P, Bhandari N, et al. Role of enteric adenoviruses and rotaviruses in mild and severe acute enteritis. Pediatr Infect Dis $J$ 1988;7:320-3.

3 Graham FL, Smiley J, Russell WC, Mairn R. Characteristics of a human cell line transformed by DNA from human tics of a human cell line transformed by DNA from

4 Martin AL, Follett EAC. An assessment of the sensitivity of three methods for the detection of rotavirus. $J$ Virol three methods for the

5 Gutman LT, Ziad IH, Gehlbach S, Blackmon L. Neonatal staphylococcal enterocolitis: Association with indwelling feeding catheters and staph aureus colonization. J Pediat 1976;88:836-9.

6 Madeley CR. Viruses in stools. J Clin Pathol 1979;32:1-10. 